\title{
Article \\ Effects of Palm Tocotrienol-Rich Fraction Alone or in Combination with Glucosamine Sulphate on Grip Strength, Cartilage Structure and Joint Remodelling Markers in a Rat Model of Osteoarthritis
}

\author{
Hiba Murtadha Al-Saadi ${ }^{1}$, Kok-Yong Chin 1,*(D), Fairus Ahmad ${ }^{2}$ (D), Elvy Suhana Mohd Ramli ${ }^{2}$, \\ Azlan Mohd Arlamsyah ${ }^{1}$, Fadhlullah Zuhair Japar Sidik ${ }^{1}$, Juliana Abdul Hamid ${ }^{1}$ and Ima Nirwana Soelaiman ${ }^{1}$ (D \\ 1 Department of Pharmacology, Faculty of Medicine, Universiti Kebangsaan Malaysia, Cheras, \\ Kuala Lumpur 56000, Malaysia; hiba.alsaadi2016@yahoo.com (H.M.A.-S.); \\ azlan.arlamsyah@ukm.edu.my (A.M.A.); jf_fakair@ppukm.ukm.edu.my (F.Z.J.S.); \\ juliana_105@ppukm.ukm.edu.my (J.A.H.); imasoel@ppukm.ukm.edu.my (I.N.S.) \\ 2 Department of Anatomy, Faculty of Medicine, Universiti Kebangsaan Malaysia, Cheras, \\ Kuala Lumpur 56000, Malaysia; fairusahmad@ukm.edu.my (F.A.); elvysuhana@ukm.edu.my (E.S.M.R.) \\ * Correspondence: chinkokyong@ppukm.ukm.edu.my; Tel.: +60-16-7082-900
}

Citation: Al-Saadi, H.M.; Chin, K.-Y.; Ahmad, F.; Mohd Ramli, E.S.; Arlamsyah, A.M.; Japar Sidik, F.Z.; Abdul Hamid, J.; Soelaiman, I.N. Effects of Palm Tocotrienol-Rich Fraction Alone or in Combination with Glucosamine Sulphate on Grip Strength, Cartilage Structure and Joint Remodelling Markers in a Rat Model of Osteoarthritis. Appl. Sci. 2021, 11, 8577. https://doi.org/ 10.3390/app11188577

Academic Editors: Paolo Alberton and Emeline Perrier-Groult

Received: 24 August 2021

Accepted: 14 September 2021

Published: 15 September 2021

Publisher's Note: MDPI stays neutral with regard to jurisdictional claims in published maps and institutional affiliations.

Copyright: (c) 2021 by the authors. Licensee MDPI, Basel, Switzerland. This article is an open access article distributed under the terms and conditions of the Creative Commons Attribution (CC BY) license (https:// creativecommons.org/licenses/by/ $4.0 /)$.
Featured Application: The combination of palm tocotrienol-rich fraction and glucosamine sulphate could be useful in reducing cartilage damage and improving knee function in osteoarthritic condition.

\begin{abstract}
Background: Osteoarthritis is a degenerative joint disease lacking disease-modifying therapeutic agents. This study aimed to compare the effects of palm tocotrienol-rich fraction (TRF), glucosamine sulphate, and both agents combined in rats with osteoarthritis induced by monosodium iodoacetate (MIA). Methods: Thirty adult male rats were randomized into normal control, and osteoarthritis groups were treated orally daily with vehicle, palm TRF (100 mg/kg), glucosamine sulphate $(250 \mathrm{mg} / \mathrm{kg})$, and both agents combined for 4 weeks. Body weight and grip strength were measured weekly. After being sacrificed, the joints and blood were harvested for histology and serum cartilage oligomeric matrix protein (COMP) levels. Results: The body weight of the rats receiving treatment rebounded significantly after an initial reduction (vs osteoarthritic control, $p<0.05$ ). The rats receiving combined treatments showed significantly better grip strength than the osteoarthritic control and individual treatment groups $(p<0.05)$. The serum COMP level was lower in all the treated groups (vs osteoarthritic control, $p<0.05$ ). Cartilage histology of the treated rats was not significantly improved (vs osteoarthritic control, $p>0.05$ ). Conclusion: The combination of palm TRF and glucosamine sulphate was more effective than individual agents in improving the grip strength of the rats, but the cartilage damage might need more time to heal.
\end{abstract}

Keywords: arthritis; cartilage oligomeric matrix protein; knee; monosodium iodoacetate; vitamin E

\section{Introduction}

Osteoarthritis is a local inflammatory joint disease marked by cartilage degeneration, synovitis and altered subchondral bone remodelling. Pathological changes in other parts of the joints, including ligaments, meniscus and infrapatellar fat pad, are also reported [1,2] Patients with osteoarthritis often suffer from joint swelling, tenderness and pain, limiting the joint motion [3,4]. According to the Global Burden of Disease Study in 2019, the worldwide prevalence of osteoarthritis was 528 million, representing a $27.5 \%$ increase from 2010 [5]. Although osteoarthritis does not contribute to mortality directly, it was the top 15 th major contributor of years lived with disability globally in 2019 [5]. If it is not managed appropriately, patients with late-stage osteoarthritis will undergo costly and invasive total arthroplasty associated with possible side effects, such as infection and bleeding [6]. 
The conventional pharmacological treatment agents for osteoarthritis, such as intraarticular corticosteroid and hyaluronan injections and oral analgesics, place emphasise on relieving the patients' symptoms $[7,8]$. Glucosamine sulphate, a substrate for proteoglycan synthesis, is one of the common alternative agents used for preventing osteoarthritis [9]. Multiple meta-analyses have reported that glucosamine sulphate could reduce pain due to osteoarthritis, with limited effects on patients' knee functions [10,11]. In addition, glucosamine sulphate exerts potent anti-inflammatory properties by suppressing translocation of nuclear factor kappa B and facilitating the degradation of cyclooxygenase enzyme [12].

Tocotrienol is a group of less common tocochromanols (Vitamin E), with four isomers $(\alpha, \beta, \gamma$, and $\delta$-tocotrienol) based on the position of the side chain. It can be found abundantly in palm oil, annatto bean and rice bran in varying composition [13]. Tocotrienol and its metabolites possess biological activities, notably anti-inflammatory effects [14]. The joint protective effects of vitamin $\mathrm{E}$ have been widely reported (summarised in [15]). Some previous studies have reported that $\gamma$-tocotrienol [16], $\delta$-tocotrienol [17] and palm TRF [18] protect against inflammatory arthritis and rheumatoid arthritis in rats. However, only one animal study ever reported the effectiveness of annatto tocotrienol rich in $\delta$-tocotrienol in preventing cartilage and subchondral bone changes [19]. Palm TRF supplementation has been attempted in an open-labelled study, with some positive outcomes in pain and functional scores, but joint structural outcomes were not tested [20]. The therapeutic potential of palm TRF in combination with other joint protective agents like glucosamine sulphate has not been assessed previously.

The current study aimed to compare the protective effects of palm TRF, glucosamine sulphate, and the combination of both agents in rats with osteoarthritis induced with monosodium iodoacetate (MIA). The parameters assessed included the body weight, grip strength, cartilage structure and serum cartilage oligomeric matrix protein (COMP) of the rats. It was hypothesised that the combination of palm TRF and glucosamine sulphate would perform better than individual agents in preventing osteoarthritis. This research will pave the way for the development of a better pharmacological regimen for reducing the morbidity caused by osteoarthritis.

\section{Materials and Methods}

\subsection{Preparation of Treatment Solution}

Palm TRF, gifted by Excelvite Sdn Bhd (Chemor, Malaysia), consisted of $12 \% \alpha, 2 \% \beta$, $19.3 \% \gamma$ and $5.5 \% \delta$-tocotrienol, as well as $11.9 \% \alpha$-tocopherol. The remaining excipient was glycerol. It was diluted with refined olive oil (Bertolli ${ }^{\mathrm{TM}}$, Deoleo, Cordoba, Spain) at a ratio of 1:10 for oral administration. Refined olive oil has the least amount of vitamin $\mathrm{E}$ and other polyphenols [21] and does not affect the progression of osteoarthritis, as shown in a rat study [19]. Palm TRF was administered at $100 \mathrm{mg} / \mathrm{kg}$ body weight as annatto tocotrienol at this dose was shown to prevent cartilage degradation in rats with osteoarthritis [19]. Glucosamine sulphate powder (Rottapharma Ltd. Dublin, Ireland) was dissolved with distilled water to form a solution of $10 \mathrm{mg} / \mathrm{mL}$ before oral administration at the dose of $250 \mathrm{mg} / \mathrm{kg}$ body weight. This dose was shown to prevent cartilage damage and joint pain in rats with osteoarthritis [22]. MIA was purchased from Sigma-Aldrich (St. Louis, USA). Four mg of MIA was dissolved with $50 \mu \mathrm{L}$ of normal saline before intra-articular injection $[19,23]$.

\subsection{Animal Treatment}

The animal handling protocols were reviewed and approved by Universiti Kebangsaan Malaysia Animal Ethics Committee (Approval code: FAR/PP/2018/KOK YONG/26SEPT./946-JAN.-2019-DEC.-2020). The Malaysian Animal Welfare Act (2015) served as the guideline of animal experimentation in this study.

Three-month-old male Sprague-Dawley rats $(\mathrm{n}=30)$ weighing 250-300 g were obtained from the laboratory animal resource unit of the authors' institution. They were kept in single pairs per plastic cage at $27^{\circ} \mathrm{C}$ and $14 / 10 \mathrm{~h}$ dark/light cycle. Standard rat 
chow (702P, Gold Coin, Port Klang, Malaysia) and tap water were provided ad libitum. After seven days of acclimatisation, the rats were randomly assigned into five groups (6 rats/group), i.e., normal control $(\mathrm{N})$, osteoarthritis control $(\mathrm{O})$, palm TRF-treated (T), glucosamine sulphate-treated $(\mathrm{G})$, and palm TRF + glucosamine sulphate-treated group $(T+G)$. Osteoarthritis was induced with MIA intra-articular injection at the right knee of the rats using a $26 \mathrm{G}$ needle under anaesthesia (ketamine/xylazine/zoletil cocktails) for all rats, except the normal control group. The oral supplementation (two times per day) was initiated the next day. During the morning session, the G and T + G groups were supplemented with glucosamine sulphate $250 \mathrm{mg} / \mathrm{kg} /$ day, while the other group received equivolume of normal saline. During the evening session, the $T$ and $T+G$ groups were supplemented with palm TRF at $100 \mathrm{mg} / \mathrm{kg} /$ day, while the other groups received equivolume of refined olive oil (Figure 1). Body weight and grip strength were measured weekly before and after osteoarthritis induction. After the 4-week treatment, the rats' blood was collected using plain tubes via cardiac puncture under anaesthesia (ketamine/xylazine/zoletil cocktails). The rats were sacrificed during cardiac puncture, and their tibial-femoral knees were collected for analysis.

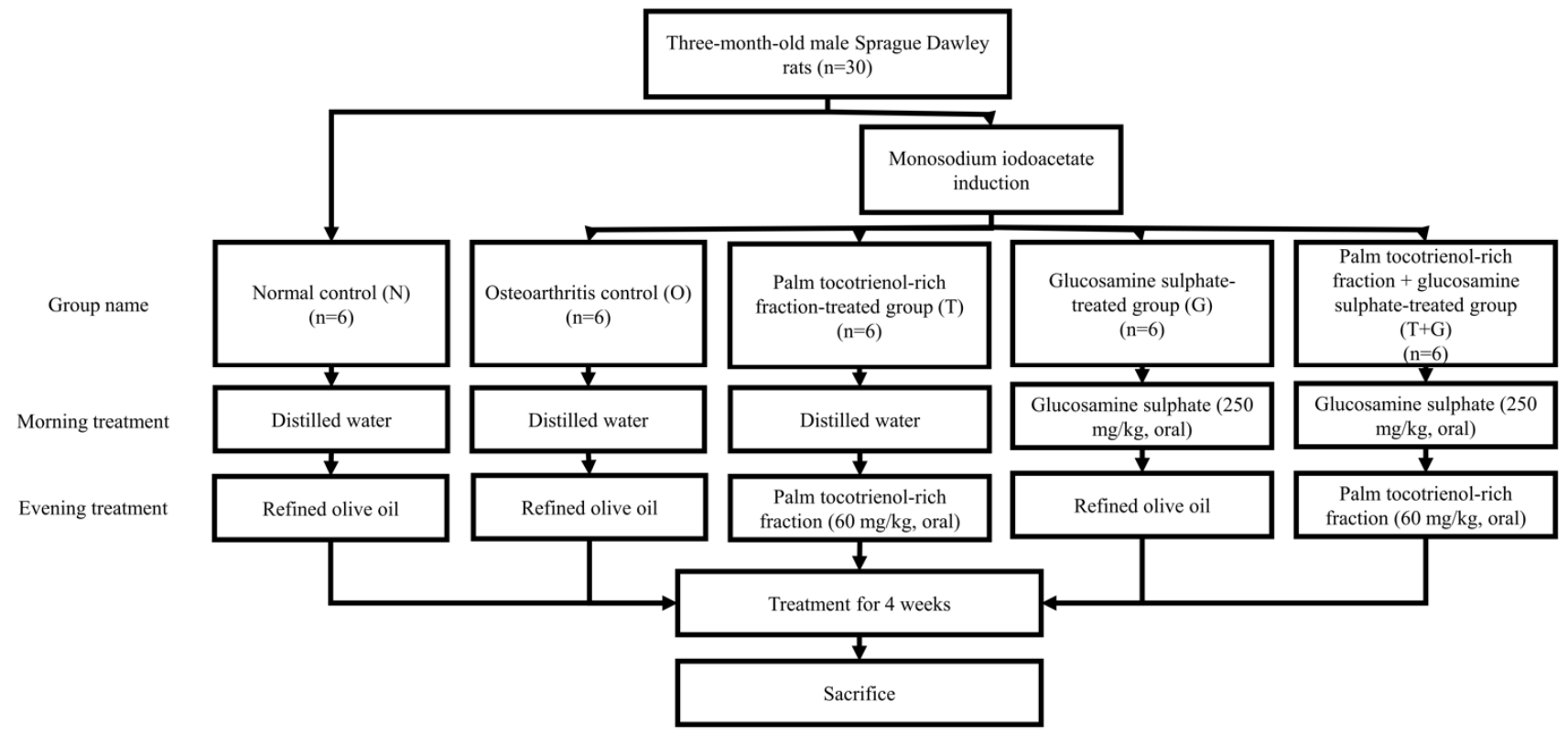

Figure 1. Treatment regimens of the rats in this study.

\subsection{Grip Strength Assessment}

The inverted screen test was used to measure the grip strength of the rats [24]. The rats were trained for one week before the initial assessment. The rats were placed at the centre of a wire mesh screen $50 \mathrm{~cm}$ above a padded surface, which was then inverted with the head of the rats reclining first. The timer was started $2 \mathrm{~s}$ after the inversion and stopped when the rats released their grip. The rats were removed if they did not fall after $2 \mathrm{~min}$.

\subsection{Histological Assessment}

The femurs with intact articular cartilage were fixed in $15 \%$ neutral buffered formalin for three days, then decalcified with 5\% formic acid (Sigma-Aldrich, St. Louis, MO, USA) for two days, and rinsed with saline for $12 \mathrm{~h}$. Next, they were immersed in an increasing concentration of ethanol (from $50 \%$ to $100 \%$ ) and toluene (50\% in ethanol and $100 \%$ ) before being embedded with paraffin (Leica Biosystem, Wetzlar, Germany). The specimens were sectioned at $8 \mu \mathrm{m}$ thickness and placed on glass slides. The tissue sections were deparaffinised in xylene and rehydrated in decreasing alcohol concentration (from 100\% to $50 \%$ ) and water. Next, the sections were stained with fast green (ScienCell Research 
Laboratory, Carlsbad, USA) for $8 \mathrm{~min}$ and rinsed with acetic acid (Sigma-Aldrich, St. Louis, MO, USA) for $10 \mathrm{~s}$. This step was followed by Safranin O staining (ScienCell Research Laboratory, Carlsbad, USA) for $30 \mathrm{~min}$. Finally, the sections were dehydrated in increasing concentrations of ethanol (from 50\% to 100\%), cleared with xylene and mounted for microscopy.

A blinded anatomist assessed the histological slides under a light microscope (Nikon Eclipse 80i, Tokyo, Japan) and scored them using the Modified Mankin's Scoring System (Table 1) [25].

Table 1. Modified Mankin's Scoring System.

\begin{tabular}{cccc}
\hline Score & Structure & Cell & Safranin O Staining \\
\hline 0 & Normal & Normal & Normal \\
1 & Surface irregularity & Diffuse hypercellularity & Slight reduction \\
2 & Pannus and surface & Cloning & Moderate reduction \\
3 & irregularity & Hypocellularity & Severe reduction \\
4 & Clefts to the transitional zone & $\mathrm{n} / \mathrm{a}$ & No dye noted \\
5 & Clefts to the radial zone & $\mathrm{n} / \mathrm{a}$ & $\mathrm{n} / \mathrm{a}$ \\
6 & Complete disorganisation & $\mathrm{n} / \mathrm{a}$ & $\mathrm{n} / \mathrm{a}$ \\
\hline
\end{tabular}

\subsection{Biochemical Assessment}

The blood collected was centrifuged for $10 \mathrm{~min}$ at $4{ }^{\circ} \mathrm{C}$ and $3000 \mathrm{rpm}$ to extract the serum, which was stored at $-70^{\circ} \mathrm{C}$ before analysis. The serum level of cartilage oligomeric matrix protein (COMP) (Cat: E-EL-R0159, Elabscience, Wuhan, China) was measured using an enzyme-linked immunosorbent assay kit following the manufacturer's instruction.

\subsection{Statistical Analysis}

The normality of the data was analysed using the Shapiro-Wilk test. Body weight and grip strength data were analysed with mixed-design analysis of variance with small effect analysis. Serum COMP data were analysed using one-way analysis of variance with Tukey post hoc test. The Mankin's scores of the joint were evaluated using the Kruskal-Wallis test, and the Mann-Whitney U-test with Bonferroni correction was used to analyse pairwise comparison. Bonferroni correction was performed to prevent inflated type I error due to multiple comparisons ( 0.05 divided by 10 pairwise comparisons, thus the adjusted $p$-value for a significant difference was $<0.005)$. Statistical analysis was performed using Statistical Software for Social Sciences version 23.0 (IBM, Armonk, NY, USA). Unless stated otherwise, $p<0.05$ was considered statistically significant.

\section{Results}

Significant time effect $(p<0.001)$ and time $\times$ group interaction $(p=0.018)$ were observed in the body weight data of the rats (Figure 2). No significant difference in rat body weight was observed among the study groups at Week 0 . One week after MIA administration, the $\mathrm{O}, \mathrm{T}, \mathrm{G}$ and $\mathrm{G}+\mathrm{T}$ groups showed a significant $(p<0.05)$ or near significant reduction ( $p=0.052, \mathrm{O}$ vs. $\mathrm{N}$ ) in body weight compared to the $\mathrm{N}$ group. The $\mathrm{N}$ group showed a significant linear increase in body weight $(p<0.05)$ starting from Week 1 but not the other groups. The body weight of the T, G and T $+\mathrm{G}$ groups started to increase significantly at Week 3 compared to Week $1(p<0.001)$. The increase was only significant for the O group at Week 4 compared to Week $3(p<0.001)$. 


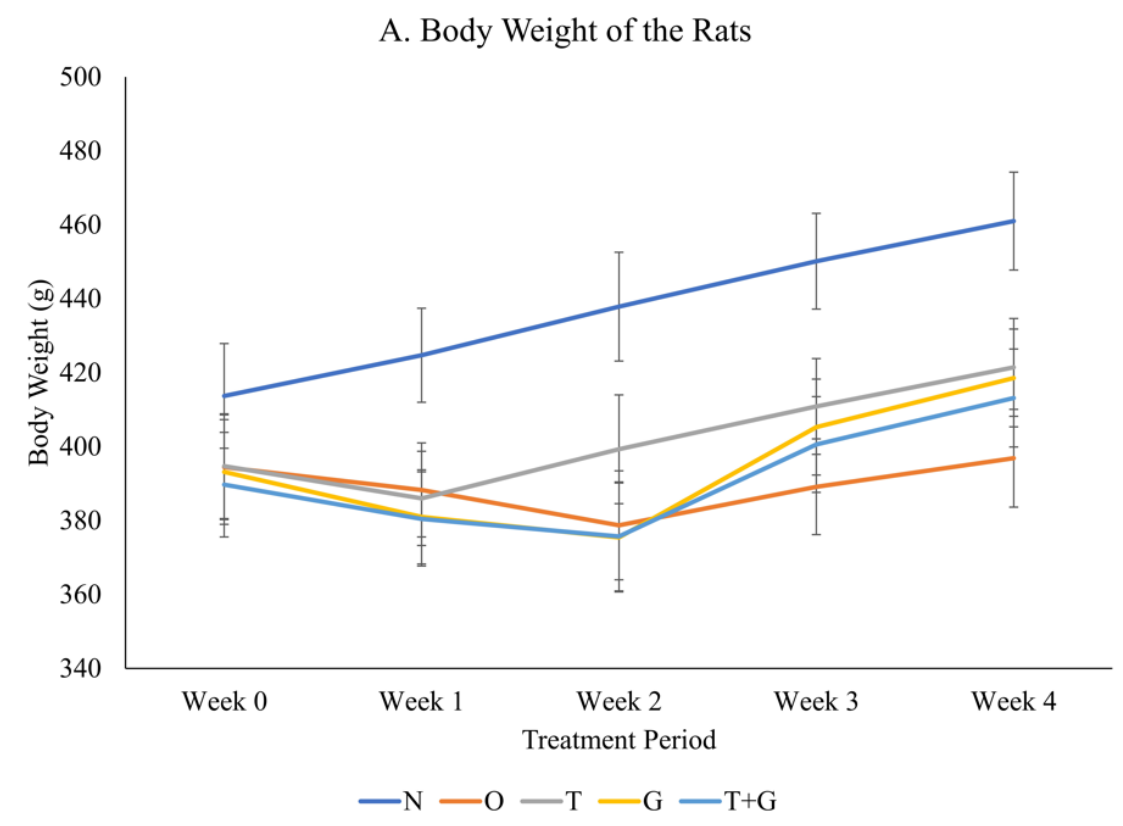

\begin{tabular}{|c|c|c|c|c|c|}
\hline \multicolumn{6}{|c|}{ B. Pairwise analysis } \\
\hline Week 0 & $\mathbf{N}$ & o & $\mathbf{T}$ & G & $\mathbf{T}+\mathbf{G}$ \\
\hline $\mathbf{N}$ & \begin{tabular}{|l} 
w $1=0.018$ \\
w $2=0.039$ \\
w $3<0.001$ \\
w $4<0.001$ \\
\end{tabular} & & & & \\
\hline o & 0.343 & $\mathrm{~ns}$ & & & \\
\hline $\mathbf{T}$ & 0.350 & 0.989 & $\begin{array}{l}\text { w } 3=0.034 \\
\text { w } 4=0.001\end{array}$ & & \\
\hline $\mathbf{G}$ & 0.313 & 0.949 & 0.938 & $\begin{array}{l}\text { w } 1=0.010 \\
\text { w } 4=0.002\end{array}$ & \\
\hline $\mathbf{T}+\mathbf{G}$ & 0.240 & 0.815 & 0.805 & 0.865 & $\begin{array}{l}\text { w } 1=0.043 \\
\text { w } 4=0.004\end{array}$ \\
\hline Week 1 & $\mathbf{N}$ & o & $T$ & G & $T+G$ \\
\hline $\mathbf{N}$ & $\begin{array}{l}\text { w } 3<0.001 \\
\text { w } 4<0.001 \\
\end{array}$ & & & & \\
\hline o & 0.052 & $\mathrm{~ns}$ & & & \\
\hline $\mathbf{T}$ & 0.040 & 0.900 & $\begin{array}{l}\text { w } 3<0.001 \\
\text { w } 4<0.001 \\
\end{array}$ & & \\
\hline G & 0.021 & 0.689 & 0.783 & $\begin{array}{l}\text { w } 3<0.001 \\
\text { w } 4<0.001\end{array}$ & \\
\hline $\mathbf{T}+\mathbf{G}$ & 0.020 & 0.666 & 0.759 & 0.975 & $\begin{array}{l}\text { w } 3<0.001 \\
\text { w } 4<0.001\end{array}$ \\
\hline Week 2 & $\mathbf{N}$ & o & $\mathbf{T}$ & G & $\mathbf{T}+\mathbf{G}$ \\
\hline $\mathbf{N}$ & w 4 $=0.018$ & & & & \\
\hline o & 0.008 & ns & & & \\
\hline$T$ & 0.074 & 0.331 & w 4 $4=0.023$ & & \\
\hline G & 0.005 & 0.876 & 0.261 & $\begin{array}{l}\text { w } 3=0.002 \\
\text { w } 4<0.001\end{array}$ & \\
\hline $\mathbf{T}+\mathbf{G}$ & 0.006 & 0.886 & 0.267 & 0.989 & $\begin{array}{l}\text { w } 3=0.009 \\
\text { w } 4<0.001\end{array}$ \\
\hline Week 3 & $\mathbf{N}$ & o & $\mathbf{T}$ & G & $\mathbf{T}+\mathbf{G}$ \\
\hline $\mathrm{N}$ & w $4<0.001$ & & & & \\
\hline o & 0.002 & w $4<0.001$ & & & \\
\hline$T$ & 0.040 & 0.245 & w $4<0.001$ & & \\
\hline G & 0.020 & 0.385 & 0.763 & w $4<0.001$ & \\
\hline $\mathbf{T}+\mathbf{G}$ & 0.011 & 0.538 & 0.579 & 0.799 & w $4<0.001$ \\
\hline Week 4 & $\mathbf{N}$ & o & $\mathbf{T}$ & G & $\mathbf{T}+\mathbf{G}$ \\
\hline $\mathbf{N}$ & As above & & & & \\
\hline o & 0.002 & As above & & & \\
\hline$T$ & 0.043 & 0.199 & As above & & \\
\hline G & 0.031 & 0.255 & 0.880 & As above & \\
\hline $\mathbf{T}+\mathbf{G}$ & 0.016 & 0.391 & 0.661 & 0.774 & As above \\
\hline
\end{tabular}

Figure 2. Body weight (mean \pm standard error) of the rats throughout the study (A). The results of inter- ( $p$-values) and intra-group comparisons (weeks that show a significant difference) obtained from mixed-design analysis of variance are depicted in (B). The values in the shaded area indicate a significant difference of the group at that week compared to other weeks (0-4). The significant difference is defined at $p<0.05$. Abbreviation: N: normal control; O: osteoarthritis control; T: palm TRF-treated group; G: glucosamine sulphate-treated group; T + G: palm TRF + glucosamine sulphate-treated group.

Significant time effect $(p=0.002)$ and not significant time $\times$ group interaction $(p=0.225)$ were observed in the retention time of the rats on the inverted wire mesh (Figure 3). No significant difference in retention time was observed among most study groups at Week $0(p>0.05)$, but the retention time of the $\mathrm{G}$ group was significantly higher than the $\mathrm{O}$ $(p=0.011)$ and T groups $(p=0.031)$. One week after MIA administration, the retention times of the $\mathrm{O}(p=0.004), \mathrm{T}(p=0.032)$ and $\mathrm{G}(p=0.042)$ groups reduced significantly compared to the $\mathrm{N}$ group. The retention time of the $\mathrm{T}+\mathrm{G}$ group was significantly higher than the $\mathrm{O}$ and $\mathrm{T}$ groups from Week 1 to $3(p<0.05)$. No significant changes in retention time were observed for the $\mathrm{N}, \mathrm{O}$ and $\mathrm{T}$ groups across the study period $(p>0.05)$. The $\mathrm{G}$ group experienced a significant drop in retention time after osteoarthritis induction but rebounded significantly at Week $4(p<0.05)$. The retention time of the $\mathrm{T}+\mathrm{G}$ group at Week 4 was also the longest compared to Weeks 1 to $3(p<0.05)$. 


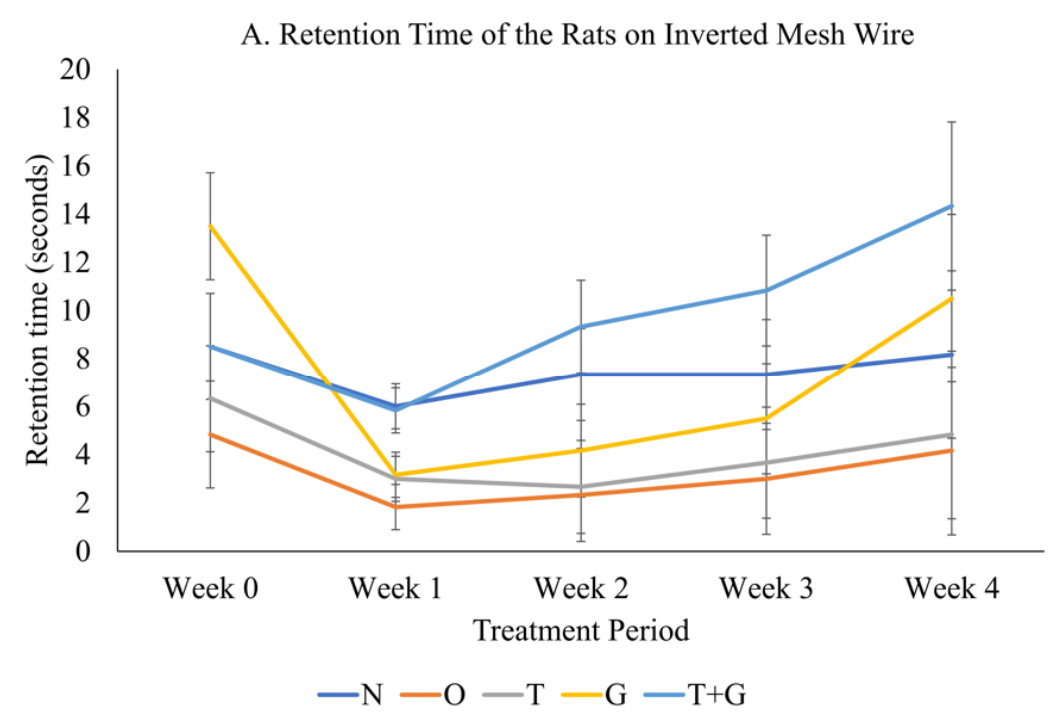

\begin{tabular}{|c|c|c|c|c|c|}
\hline Week 0 & $\mathbf{N}$ & O & $\mathbf{T}$ & G & $\mathbf{T}+\mathbf{G}$ \\
\hline $\mathbf{N}$ & ns & & & & \\
\hline $\mathbf{O}$ & 0.253 & ns & & & \\
\hline $\mathbf{T}$ & 0.496 & 0.636 & ns & & \\
\hline G & 0.123 & 0.011 & 0.031 & $\begin{array}{l}\text { w } 1<0.001 \\
\text { w } 2=0.002 \\
\text { w } 3=0.007\end{array}$ & \\
\hline $\mathbf{T}+\mathbf{G}$ & 1.000 & 0.253 & 0.496 & 0.123 & ns \\
\hline Week 1 & $\mathbf{N}$ & o & $\mathbf{T}$ & G & $\mathbf{T}+\mathbf{G}$ \\
\hline $\mathbf{N}$ & ns & & & & \\
\hline o & 0.004 & ns & & & \\
\hline $\mathbf{T}$ & 0.032 & 0.385 & ns & & \\
\hline G & 0.042 & 0.322 & 0.900 & w $4=0.022$ & \\
\hline $\mathbf{T}+\mathbf{G}$ & 0.900 & 0.006 & 0.042 & 0.054 & $\begin{array}{l}\text { w } 2=0.016 \\
\text { w } 3=0.012 \\
\text { w } 4=0.009\end{array}$ \\
\hline Week 2 & $\mathrm{~N}$ & $\mathbf{O}$ & $\mathbf{T}$ & G & $\mathbf{T}+\mathbf{G}$ \\
\hline $\mathbf{N}$ & ns & & & & \\
\hline O & 0.078 & ns & & & \\
\hline $\mathbf{T}$ & 0.098 & 0.903 & ns & & \\
\hline G & 0.255 & 0.506 & 0.586 & w $4=0.015$ & \\
\hline $\mathbf{T}+\mathbf{G}$ & 0.469 & 0.016 & 0.022 & 0.069 & w $4=0.049$ \\
\hline Week 3 & $\mathbf{N}$ & $\mathbf{O}$ & $\mathbf{T}$ & G & $\mathbf{T}+\mathbf{G}$ \\
\hline $\mathbf{N}$ & ns & & & & \\
\hline o & 0.194 & ns & & & \\
\hline $\mathbf{T}$ & 0.270 & 0.839 & ns & & \\
\hline G & 0.577 & 0.449 & 0.577 & w $4=0.003$ & \\
\hline $\mathbf{T}+\mathbf{G}$ & 0.291 & 0.024 & 0.037 & 0.113 & w $4=0.031$ \\
\hline Week 4 & $\mathbf{N}$ & o & $\mathbf{T}$ & G & $\mathbf{T}+\mathbf{G}$ \\
\hline $\mathbf{N}$ & As above & & & & \\
\hline o & 0.425 & As above & & & \\
\hline $\mathbf{T}$ & 0.505 & 0.893 & As above & & \\
\hline G & 0.640 & 0.211 & 0.261 & As above & \\
\hline $\mathbf{T}+\mathbf{G}$ & 0.222 & 0.050 & 0.065 & 0.444 & As above \\
\hline
\end{tabular}

Figure 3. Grip strength (mean \pm standard error) of the rats throughout the study (A). The results of inter- $(p$-values) and intra-group comparisons (weeks that show a significant difference) obtained from mixed-design analysis of variance are depicted in (B). The values in the shaded area indicate a significant difference of the group at that week compared to other weeks (0-4). The significant difference is defined at $p<0.05$. Abbreviation: ns: no significant difference; N: normal control; O: osteoarthritis control; T: palm TRF-treated group; G: glucosamine sulphate-treated group; T + G: palm TRF + glucosamine sulphate-treated group; ns = not significant.

The Kruskal-Wallis test revealed a significant difference in structural $(p=0.002)$, matrix $(p=0.002)$, cellular $(p=0.012)$, and total scores $(p=0.003)$ among the study groups (Figure 4$)$. The $\mathrm{G}(p=0.001)$ and $\mathrm{T}+\mathrm{G}$ groups $(p=0.001)$ showed significantly higher structural scores than the $\mathrm{N}$ group. The $\mathrm{T}$ and $\mathrm{G}$ groups showed significantly higher matrix scores than the $\mathrm{N}$ group $(p=0.001)$. The $\mathrm{O}$ group showed significantly higher cellular scores than the $\mathrm{N}$ group $(p=0.001)$. All rats with osteoarthritis had significantly higher total Mankin's score than the $\mathrm{N}$ group ( $p=0.002$ vs. $\mathrm{O}, \mathrm{T}, \mathrm{G}$ and $\mathrm{T}+\mathrm{G}$ group).

Serum COMP level was significantly higher in the $\mathrm{O}$ group than the $\mathrm{N}, \mathrm{T}, \mathrm{G}$ and $\mathrm{T}+\mathrm{G}$ groups $(p<0.001)$. However, no significance was observed between the $\mathrm{N}$ and all treatment groups $(p>0.05)$, nor among the treatment groups $(p>0.05)$ (Figure 5). 

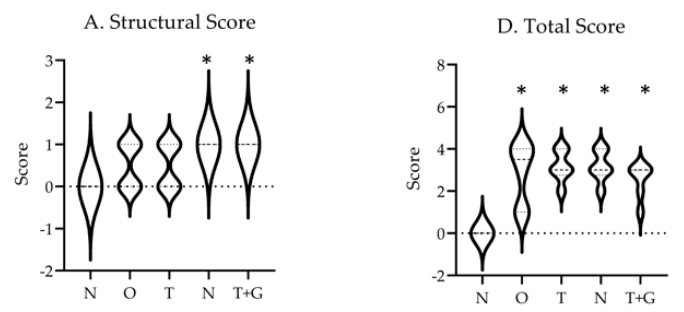

B. Matrix Score

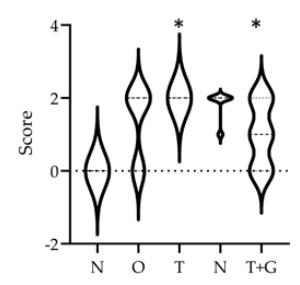

C. Cellular Score

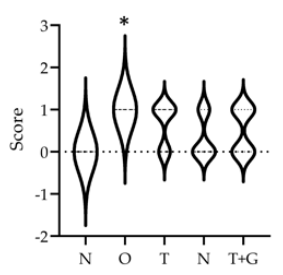

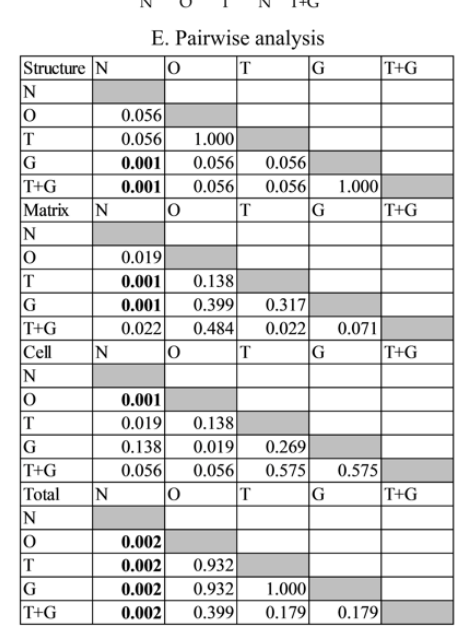

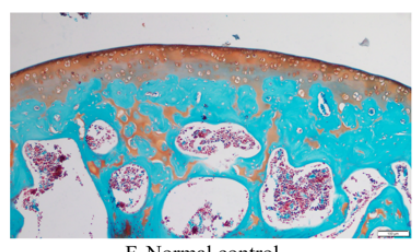

F. Normal control

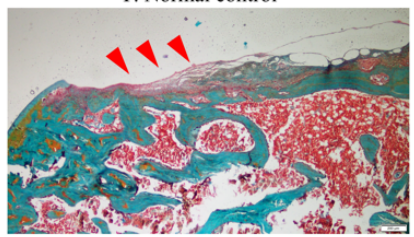

G. Osteoarthritis control

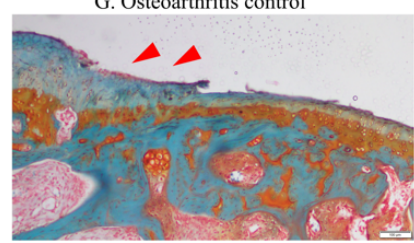

H. Palm TRF-treated

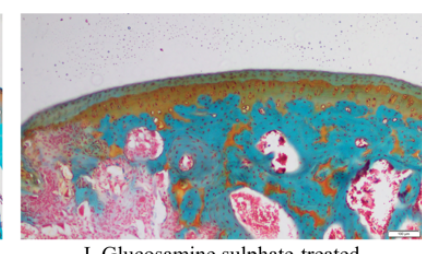

I. Glucosamine sulphate-treated

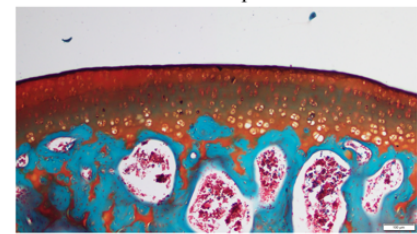

J. Palm TRF+Glucosamine sulphatetreated

Figure 4. Mankin's score (range of scores in violin plot) for the cartilage structure of the rats (A-D). The results of inter-group comparison ( $p$-values) obtained from the Mann-Whitney U-test are depicted in (E). The significant difference is defined at $p<0.005$ after Bonferroni correction. The representative photomicrographs (magnification: $20 \times$ ) of each group are presented in (F-J) ((F): normal control; G: osteoarthritis control; (H): palm TRF-treated group; (I): glucosamine sulphate-treated group; (J): palm TRF + glucosamine sulphate-treated group). Significant cartilage deterioration (red arrow heads) was observed for the $\mathrm{O}$ group, and lesions were still observed for all treated groups. Abbreviation: *: significant difference compared to the $\mathrm{N}$ group; N: normal control; O: osteoarthritis control; T: palm TRF-treated group; G: glucosamine sulphate-treated group; $\mathrm{T}+\mathrm{G}$ : palm TRF + glucosamine sulphate-treated group.

A. Serum cartilage oligomeric matrix protein level

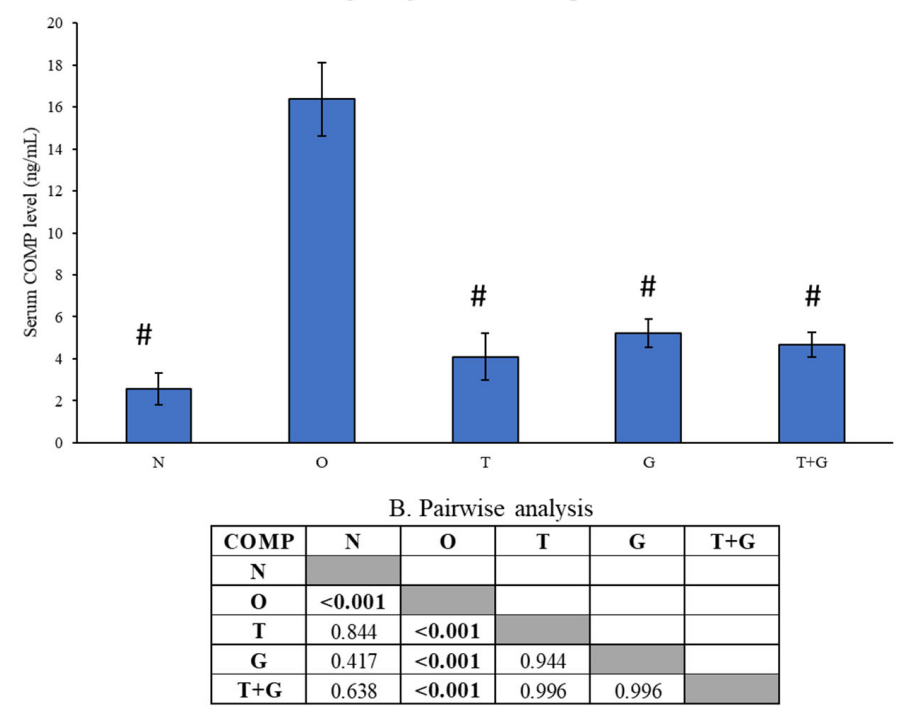

Figure 5. Serum level of cartilage oligomeric matrix protein (COMP) of the rats (A). The results of inter-group comparison ( $p$-values) obtained from the Tukey post hoc test are depicted in (B). The significant difference is defined at $p<0.05$. Abbreviation: \#: significant difference compared to the O group; N: normal control; O: osteoarthritis control; T: palm TRF-treated group; G: glucosamine sulphate-treated group; $\mathrm{T}+\mathrm{G}$ : palm TRF + glucosamine sulphate-treated group. 


\section{Discussion}

The current study compared the anti-osteoarthritic effects of palm TRF, glucosamine sulphate, and both agents in combination in a rat model of osteoarthritis induced by MIA. It revealed that all treatment regimens halted the cartilage deterioration process in the rat joints induced with MIA, as illustrated via the serum COMP level. However, the joint lesions caused by MIA might not have healed completely, as demonstrated by the joint histology. From the functional aspect, the combination of palm TRF and glucosamine significantly increased the grip strength of rats with $\mathrm{OA}$, and the effects were better than each agent used alone. The improved joint function might enable the rats to reach for food and maintain their body weight.

MIA inhibits glyceraldehyde-3-phosphate dehydrogenase involved in the glycolysis. Treating chondrocytes with MIA has been shown to cause mitochondrial dysfunction and, subsequently, cell death [26,27]. In another study, MIA arrested chondrocyte proliferation due to S-phase arrest [28]. MIA has been commonly used to induce cartilage damage in animals to mimic osteoarthritis in humans [29-31]. In this study, MIA induced apparent cartilage damage, as similarly observed in previous studies [19,32]. However, quantifying the damage using a modified Mankin's score revealed no statistically significant changes between the $\mathrm{N}$ and $\mathrm{O}$ group in the structural, matrix, and cellular scores. This observation was probably due to the narrow range of scores of each component between these two groups (all 0 in the $\mathrm{N}$ group, $0-2$ in the $\mathrm{O}$ group). The total Mankin's score for the $\mathrm{O}$ group was significantly higher than for the $\mathrm{N}$ group, indicating more degenerative features in rats induced with MIA.

On the other hand, all treatment groups showed varying degrees of cartilage damage compared to the $\mathrm{N}$ group. The Mankin's score for each joint component was inconsistent between the treatment groups and the control groups. The total Mankin's score revealed that the overall joint damage in the treatment groups was similar to the $\mathrm{O}$ group. In contrast, a previous study showed that annatto tocotrienol (100-150 mg $/ \mathrm{kg}$ for one month) suppressed joint damage in a rat model of osteoarthritis induced by MIA [19]. The distinction in the composition between palm TRF and annatto tocotrienol might be responsible for the difference. In the inflammatory/rheumatoid arthritis model, $\gamma$-tocotrienol $(5 \mathrm{mg} / \mathrm{kg}$ for 25 days) [16], $\delta$-tocotrienol (10 mg/kg for 25 days) [17] and palm TRF ( $30 \mathrm{mg} / \mathrm{kg}$ for 25 days) [18] were shown to reduce degenerative joint changes in rats. Based on the dosage used in these studies, palm TRF may not be as potent as pure $\gamma$ and $\delta$-tocotrienol in preventing joint damage due to arthritis, thus necessitating a higher dose to achieve the same protective effects. Meanwhile, in a previous study, supplementation of glucosamine sulphate $(250 \mathrm{mg} / \mathrm{kg})$ was shown to attenuate but not completely prevent cartilage damage in a rat model of osteoarthritis induced by anterior cruciate ligament transection [22]. In contrast, cartilage lesions were still present in the current study in rats supplemented with the same dose of glucosamine sulphate. The MIA-induced osteoarthritis model used in this study could induced more intense cartilage damage than other models, thus requiring more time to heal even with glucosamine sulphate supplementation.

COMP is a pentameric extracellular matrix glycoprotein found in the cartilage and other joint tissues (synovium, ligaments, tendons and fibroblasts) [33]. It is a sensitive marker of cartilage degradation in osteoarthritis and rheumatoid arthritis [33]. Its level increases in the early stage of osteoarthritis and subsequently decreases in late-stage disease [34]. In the present study, the rats with osteoarthritis showed a significantly higher COMP than the normal rats, indicating an ongoing damage process in the joint. All treatment regimens suppressed COMP levels, but no significant difference was observed among them. This observation implies that the damage process has stopped. Considering the histological results together, palm TRF, glucosamine sulphate, and the combination of both can halt cartilage deterioration, but it takes more time for the cartilage lesions to heal completely.

MIA-induced osteoarthritis model was reported to reflect pain, mechanical and temperature hypersensitivity [35]. Owing to these changes, rats of this disease model also 
demonstrated reduced hindpaw grip strength, as measured via the digital grip strength meter [36]. Due to the absence of a similar device in the authors' setting, an inverted screen grip strength test was used [24]. This test has been adopted by multiples studies as a functional assessment of rodents in various disease models [37,38]. Upon osteoarthritis induction, a significant decrease in grip strength was noted for all rats, except the $T+G$ group. Two weeks after induction, the difference in grip strength between the $\mathrm{N}$ and $\mathrm{O}$ groups was not significant, but the $\mathrm{T}+\mathrm{G}$ group continued to show significantly better performance than the $\mathrm{O}$ and $\mathrm{T}$ group. This observation reflects a rapid and continuous protection of joint function by the palm TRF and glucosamine sulphate in combination. Given that cartilage lesions were still found in the combination group, other factors might contribute to the improvement in grip strength. Inflammatory pain is associated with prostaglandins release mediated by cyclooxygenase [39]. $\gamma$-tocotrienol could decrease cyclooxygenase-2 expression in human gastric cancer cells [40]. Palm TRF (25-100 mg/kg for 4 weeks) has been reported to suppress hyperalgesia and allodynia in a rat model of diabetic neuropathy due to reduced inflammation and nitrosative stress [41]. A meta-analysis showed that glucosamine sulphate effectively reduces pain in patients with osteoarthritis, probably owing to its anti-inflammatory effects [42]. Although antinociceptive effects of the regimens were not assessed in this study, the anti-inflammatory functions of both TRF and glucosamine sulphate could have contributed to the increased grip strength of the animals.

Besides, MIA induction also caused an initial reduction in body weight of rats in this study, which rebounded after 2-3 weeks. Previous studies have reported that osteoarthritis induced by MIA is associated with the altered locomotion of rats, particularly the rearing and standing activities necessary when the rats reach for food [43,44]; this is probably due to joint pain. Thus, the reduction in body weight observed in this study might be associated with reduced food intake, although it was not recorded by the researchers. Furthermore, the rats receiving treatments regained body weight faster than the untreated rats with osteoarthritis, implying faster function recovery, which coincides with grip strength data.

The current study is not without its limitations. Grip strength is the only functional outcome measured due to the technical limitations of the authors' laboratory. Weightbearing and rearing activities should be monitored in future studies. The mechanism of palm TRF and glucosamine sulphate in preventing osteoarthritis is not reported in the current study. The inflammatory, oxidative stress and cartilage markers in joint tissues such as cartilage, synovium and infrapatellar fat pad should be investigated in future studies. Nevertheless, this study has highlighted the potential additive effects of palm TRF and glucosamine sulphate in preventing osteoarthritis and, especially, improving the functional outcomes for the rats. This effect should be investigated further for potential application in patients with osteoarthritis.

\section{Conclusions}

Palm TRF and glucosamine sulphate alone or in combination lower serum COMP levels but do not produce a significant change in modified Mankin's score within 4 weeks. It is speculated that the treatment regimens halt the cartilage degradation process in rats with osteoarthritis, although complete healing of cartilage lesions would require a longer period of treatment. The combination of palm TRF and glucosamine sulphate could increase the grip strength of rats with osteoarthritis better than an individual agent alone, which may be independent of cartilage healing. Rats treated with the combinatorial regimens also sustained their body weight better than individual agents alone. Further studies should investigate biochemical changes in the joints, particularly those due to inflammation and oxidative stress, under the influence of these agents to illustrate their mechanisms of action.

\section{Patent}

The authors have filed a patent application under the number UKM.IKB.800-4/1/3950. 
Author Contributions: Conceptualization, K.-Y.C., F.A., E.S.M.R. and I.N.S.; methodology, H.M.A.-S., A.M.A., F.Z.J.S. and J.A.H.; validation, K.-Y.C., F.A. and E.S.M.R.; formal analysis, K.-Y.C., F.A. and H.M.A.-S.; investigation, H.M.A.-S., A.M.A., F.Z.J.S. and J.A.H.; resources, K.-Y.C., F.A., E.S.M.R.; data curation, H.M.A.-S. and K.-Y.C.; writing-original draft preparation, H.M.A.-S. and K.-Y.C.; writing-review and editing, I.N.S.; visualization, K.-Y.C.; supervision, K.-Y.C. and I.N.S.; project administration, H.M.A.-S.; funding acquisition, K.-Y.C., F.A., E.S.M.R. and I.N.S. All authors have read and agreed to the published version of the manuscript.

Funding: The authors of this study are supported by Universiti Kebangsaan Malaysia via Research University Grant (GUP-2020-021).

Institutional Review Board Statement: The animal handling protocols were reviewed and approved by Universiti Kebangsaan Malaysia Animal Ethics Committee (Approval code: FAR/PP/2018/KOK YONG/26-SEPT./946-JAN.-2019-DEC.-2020).

Informed Consent Statement: This study does not involve human subjects.

Data Availability Statement: Data of this study will be made available upon request to the corresponding author.

Acknowledgments: The authors thank Universiti Kebangsaan Malaysia for funding this study via Research University Grant (GUP-2020-021) and technicians from the Department of Pharmacology for their assistance. The authors also thank Haider Jaafar Hussein Chilabi for designing and standardising the inverted mesh wire test and Kok-Lun Pang and Sophia Ogechi Ekeuku for proofreading the manuscript.

Conflicts of Interest: The authors declare no conflict of interest. The funders/sponsors had no role in the design of the study; in the collection, analyses, or interpretation of data; in the writing of the manuscript, or in the decision to publish the results.

\section{References}

1. Belluzzi, E.; Macchi, V.; Fontanella, C.G.; Carniel, E.L.; Olivotto, E.; Filardo, G.; Sarasin, G.; Porzionato, A.; Granzotto, M.; Pozzuoli, A.; et al. Infrapatellar Fat Pad Gene Expression and Protein Production in Patients with and without Osteoarthritis. Int. J. Mol. Sci. 2020, 21, 6016. [CrossRef] [PubMed]

2. Poole, A.R. Osteoarthritis as a whole joint disease. HSS J. 2012, 8, 4-6. [CrossRef]

3. Dell'Isola, A.; Steultjens, M. Classification of patients with knee osteoarthritis in clinical phenotypes: Data from the osteoarthritis initiative. PLoS ONE 2018, 13, e0191045. [CrossRef] [PubMed]

4. Lespasio, M.J.; Piuzzi, N.S.; Husni, M.E.; Muschler, G.F.; Guarino, A.; Mont, M.A. Knee Osteoarthritis: A Primer. Perm. J. 2017, 21, 16-183. [CrossRef]

5. Global Burden of Disease Collaborative Network. Global Burden of Disease Study 2019 (GBD 2019) Results. Osteoarthritis-Level 3 Cause. Available online: http:/ / www.healthdata.org/results/gbd_summaries/2019/osteoarthritis-level-3-cause (accessed on 15 June 2021).

6. Courtney, P.M.; Boniello, A.J.; Berger, R.A. Complications Following Outpatient Total Joint Arthroplasty: An Analysis of a National Database. J. Arthroplast. 2017, 32, 1426-1430. [CrossRef]

7. Abramoff, B.; Caldera, F.E. Osteoarthritis: Pathology, Diagnosis, and Treatment Options. Med. Clin. N. Am. 2020, $104,293-311$. [CrossRef]

8. Walter, H.; Sevdalina, L.; Ulf, M.-L. Current Treatment Options for Osteoarthritis. Curr. Rheumatol. Rev. 2018, 14, 108-116.

9. Al-Saadi, H.M.; Pang, K.-L.; Ima-Nirwana, S.; Chin, K.-Y. Multifaceted Protective Role of Glucosamine against Osteoarthritis: Review of Its Molecular Mechanisms. Sci. Pharm. 2019, 87, 34. [CrossRef]

10. Ogata, T.; Ideno, Y.; Akai, M.; Seichi, A.; Hagino, H.; Iwaya, T.; Doi, T.; Yamada, K.; Chen, A.Z.; Li, Y.; et al. Effects of glucosamine in patients with osteoarthritis of the knee: A systematic review and meta-analysis. Clin. Rheumatol. 2018, 37, 2479-2487. [CrossRef] [PubMed]

11. Simental-Mendía, M.; Sánchez-García, A.; Vilchez-Cavazos, F.; Acosta-Olivo, C.A.; Peña-Martínez, V.M.; Simental-Mendía, L.E. Effect of glucosamine and chondroitin sulfate in symptomatic knee osteoarthritis: A systematic review and meta-analysis of randomized placebo-controlled trials. Rheumatol. Int. 2018, 38, 1413-1428. [CrossRef] [PubMed]

12. du Souich, P. Absorption, distribution and mechanism of action of SYSADOAS. Pharm. Ther. 2014, 142, 362-374. [CrossRef]

13. Chin, K.Y.; Ima-Nirwana, S. The Role of Tocotrienol in Preventing Male Osteoporosis-A Review of Current Evidence. Int. J. Mol. Sci. 2019, 20, 1355. [CrossRef]

14. Wong, S.K.; Kamisah, Y.; Mohamed, N.; Muhammad, N.; Masbah, N.; Fahami, N.A.M.; Mohamed, I.N.; Shuid, A.N.; Saad, Q.M.; Abdullah, A.; et al. Potential Role of Tocotrienols on Non-Communicable Diseases: A Review of Current Evidence. Nutrients 2020, 12, 259. [CrossRef] [PubMed] 
15. Chin, K.Y.; Ima-Nirwana, S. The Role of Vitamin E in Preventing and Treating Osteoarthritis-A Review of the Current Evidence. Front. Pharm. 2018, 9, 946. [CrossRef] [PubMed]

16. Radhakrishnan, A.; Tudawe, D.; Chakravarthi, S.; Chiew, G.S.; Haleagrahara, N. Effect of $\gamma$-tocotrienol in counteracting oxidative stress and joint damage in collagen-induced arthritis in rats. Exp. Ther. Med. 2014, 7, 1408-1414. [CrossRef] [PubMed]

17. Haleagrahara, N.; Swaminathan, M.; Chakravarthi, S.; Radhakrishnan, A. Therapeutic Efficacy of Vitamin E Tocotrienol in Collagen-Induced Rat Model of Arthritis. BioMed Res. Int. 2014, 2014, 539540. [CrossRef] [PubMed]

18. Zainal, Z.; Rahim, A.A.; Radhakrishnan, A.K.; Chang, S.K.; Khaza'ai, H. Investigation of the curative effects of palm vitamin E tocotrienols on autoimmune arthritis disease in vivo. Sci. Rep. 2019, 9, 16793. [CrossRef]

19. Chin, K.-Y.; Wong, S.K.; Japar Sidik, F.Z.; Abdul Hamid, J.; Abas, N.H.; Mohd Ramli, E.S.; Afian Mokhtar, S.; Rajalingham, S.; Ima Nirwana, S. The Effects of Annatto Tocotrienol Supplementation on Cartilage and Subchondral Bone in an Animal Model of Osteoarthritis Induced by Monosodium Iodoacetate. Int. J. Environ. Res. Public Health 2019, 16, 2897. [CrossRef] [PubMed]

20. Haflah, N.H.; Jaarin, K.; Abdullah, S.; Omar, M. Palm vitamin E and glucosamine sulphate in the treatment of osteoarthritis of the knee. Saudi Med. J. 2009, 30, 1432-1438.

21. Aresta, A.; Zambonin, C. Determination of $\alpha$-Tocopherol in Olive Oil by Solid-Phase Microextraction and Gas ChromatographyMass Spectrometry. Anal. Lett. 2017, 50, 1580-1592. [CrossRef]

22. Wen, Z.H.; Tang, C.C.; Chang, Y.C.; Huang, S.Y.; Hsieh, S.P.; Lee, C.H.; Huang, G.S.; Ng, H.F.; Neoh, C.A.; Hsieh, C.S.; et al. Glucosamine sulfate reduces experimental osteoarthritis and nociception in rats: Association with changes of mitogen-activated protein kinase in chondrocytes. Osteoarthr. Cartil. 2010, 18, 1192-1202. [CrossRef] [PubMed]

23. Khotib, J.; Pratiwi, A.P.; Ardianto, C.; Rahmadi, M. Attenuation of IL-1ß on the use of glucosamine as an adjuvant in meloxicam treatment in rat models with osteoarthritis. J. Basic Clin. Physiol. Pharm. 2019, 30. [CrossRef]

24. Deacon, R.M.J. Measuring the strength of mice. J. Vis. Exp. 2013, 76, 2610. [CrossRef]

25. Ma, C.H.; Lv, Q.; Yu, Y.X.; Zhang, Y.; Kong, D.; Niu, K.R.; Yi, C.Q. Protective effects of tumor necrosis factor- $\alpha$ blockade by adalimumab on articular cartilage and subchondral bone in a rat model of osteoarthritis. Braz. J. Med. Biol. Res. 2015, 48, 863-870. [CrossRef]

26. Huang, L.W.; Huang, T.C.; Hu, Y.C.; Hsieh, B.S.; Chiu, P.R.; Cheng, H.L.; Chang, K.L. Zinc protects chondrocytes from monosodium iodoacetate-induced damage by enhancing ATP and mitophagy. Biochem. Biophys. Res. Commun. 2020, 521, 50-56. [CrossRef]

27. Jiang, L.; Li, L.; Geng, C.; Gong, D.; Jiang, L.; Ishikawa, N.; Kajima, K.; Zhong, L. Monosodium iodoacetate induces apoptosis via the mitochondrial pathway involving ROS production and caspase activation in rat chondrocytes in vitro. J. Orthop. Res. 2013, 31, 364-369. [CrossRef]

28. Pang, K.-L.; Chow, Y.Y.; Leong, L.M.; Law, J.X.; Ghafar, N.A.; Soelaiman, I.N.; Chin, K.-Y. Establishing SW1353 Chondrocytes as a Cellular Model of Chondrolysis. Life 2021, 11, 272. [CrossRef]

29. Lee, M.; Kim, D.; Park, S.J.; Yun, J.M.; Oh, D.H.; Lee, J. Antarctic Krill Oil Ameliorates Monosodium Iodoacetate-Induced Irregularities in Articular Cartilage and Inflammatory Response in the Rat Models of Osteoarthritis. Nutrients 2020, 12, 3550. [CrossRef]

30. Okuyan, H.M.; Terzi, M.Y.; Karaboğa, İ; Doğan, S.; Kalacı, A. In vivo protective effects of upper zone of growth plate and cartilage matrix associated protein against cartilage degeneration in a monosodium iodoacetate induced osteoarthritis model. Can. J. Physiol. Pharm. 2020, 98, 763-770. [CrossRef] [PubMed]

31. Shin, M.R.; Lee, J.A.; Kim, M.J.; Park, H.J.; Park, B.W.; Seo, S.B.; Roh, S.S. Protective Effects of Phellinus linteus Mycelium on the Development of Osteoarthritis after Monosodium Iodoacetate Injection. Evid. Based Complement. Altern. Med. 2020, 2020, 7240858. [CrossRef] [PubMed]

32. Sahin, K.; Kucuk, O.; Orhan, C.; Tuzcu, M.; Durmus, A.S.; Ozercan, I.H.; Sahin, N.; Juturu, V. Niacinamide and undenatured type II collagen modulates the inflammatory response in rats with monoiodoacetate-induced osteoarthritis. Sci. Rep. 2021, 11, 14724. [CrossRef]

33. Posey, K.L.; Coustry, F.; Hecht, J.T. Cartilage oligomeric matrix protein: COMPopathies and beyond. Matrix Biol. 2018, 71-72, 161-173. [CrossRef]

34. Munjal, A.; Bapat, S.; Hubbard, D.; Hunter, M.; Kolhe, R.; Fulzele, S. Advances in Molecular biomarker for early diagnosis of Osteoarthritis. Biomol. Concepts 2019, 10, 111-119. [CrossRef]

35. Yamada, E.F.; Salgueiro, A.F.; Goulart, A.D.S.; Mendes, V.P.; Anjos, B.L.; Folmer, V.; da Silva, M.D. Evaluation of monosodium iodoacetate dosage to induce knee osteoarthritis: Relation with oxidative stress and pain. Int. J. Rheum. Dis. 2019, 22, 399-410. [CrossRef]

36. Batallé, G.; Cabarga, L.; Pol, O. The Inhibitory Effects of Slow-Releasing Hydrogen Sulfide Donors in the Mechanical Allodynia, Grip Strength Deficits, and Depressive-Like Behaviors Associated with Chronic Osteoarthritis Pain. Antioxidants 2020, 9, 31. [CrossRef] [PubMed]

37. Segatto, M.; Szokoll, R.; Fittipaldi, R.; Bottino, C.; Nevi, L.; Mamchaoui, K.; Filippakopoulos, P.; Caretti, G. BETs inhibition attenuates oxidative stress and preserves muscle integrity in Duchenne muscular dystrophy. Nat. Commun. 2020, $11,6108$. [CrossRef] 
38. Englander, Z.K.; Wei, H.-J.; Pouliopoulos, A.N.; Bendau, E.; Upadhyayula, P.; Jan, C.-I.; Spinazzi, E.F.; Yoh, N.; Tazhibi, M.; McQuillan, N.M.; et al. Focused ultrasound mediated blood-brain barrier opening is safe and feasible in a murine pontine glioma model. Sci. Rep. 2021, 11, 6521. [CrossRef] [PubMed]

39. Yam, M.F.; Loh, Y.C.; Tan, C.S.; Khadijah Adam, S.; Abdul Manan, N.; Basir, R. General Pathways of Pain Sensation and the Major Neurotransmitters Involved in Pain Regulation. Int. J. Mol. Sci. 2018, 19, 2164. [CrossRef] [PubMed]

40. Zhang, Y.H.; Ma, K.; Liu, J.R.; Wang, H.X.; Tian, W.X.; Tu, Y.H.; Sun, W.G. $\gamma$-tocotrienol inhibits the invasion and migration of human gastric cancer cells through downregulation of cyclooxygenase-2 expression. Oncol. Rep. 2018, 40, 999-1007. [CrossRef]

41. Kuhad, A.; Chopra, K. Tocotrienol attenuates oxidative-nitrosative stress and inflammatory cascade in experimental model of diabetic neuropathy. Neuropharmacology 2009, 57, 456-462. [CrossRef]

42. Knapik, J.J.; Pope, R.; Hoedebecke, S.S.; Schram, B.; Orr, R.; Lieberman, H.R. Effects of Oral Glucosamine Sulfate on OsteoarthritisRelated Pain and Joint-Space Changes: Systematic Review and Meta-Analysis. J. Spec. Oper. Med. 2018, 18, 139-147. [PubMed]

43. Nagase, H.; Kumakura, S.; Shimada, K. Establishment of a novel objective and quantitative method to assess pain-related behavior in monosodium iodoacetate-induced osteoarthritis in rat knee. J. Pharm. Toxicol. Methods 2012, 65, 29-36. [CrossRef]

44. Alsalem, M.; Haddad, M.; Altarifi, A.; Aldossary, S.A.; Kalbouneh, H.; Abojaradeh, A.M.; El-Salem, K. Impairment in locomotor activity as an objective measure of pain and analgesia in a rat model of osteoarthritis. Exp. Ther. Med. 2020, 20, 165. [CrossRef] [PubMed] 